\title{
AVALIAÇÃO DA GERMINAÇÃO DE SEMENTES DE MILHO TRATADAS COM EXTRATO
} DE CONFREI (Symphytum officinale)

\author{
Wilson Rubens Datsch, Fabiana Lima Abrantes, Luciana de Oliveira Derré \\ Faculdade Centro Mato-Grossense, Curso de Agronomia, Sorriso, MT. E-mail: luciana derre@hotmail.com
}

\begin{abstract}
RESUMO
A cultura do milho tem uma grande importância econômica no Brasil e necessita aumentar a produtividade. Estudos estão ocorrendo em busca da substituição de produtos químicos por produtos orgânicos, o que poderia reduzir os custos de produção e os riscos ambientais. 0 objetivo deste trabalho foi avaliar o efeito de diferentes concentrações do extrato de confrei na germinação do milho. O experimento foi conduzido na Faculdade Centro Mato-Grossense (FACEM), Sorriso (MT), no Laboratório de Microbiologia, onde avaliou-se a germinação, índice de velocidade de germinação (IVG), comprimento radicular e de parte aérea, através de cinco tratamentos com 50 sementes dispostas equidistantemente, com cinco repetições cada. Os tratamentos diferenciaram de acordo com as concentrações do extrato de confrei em água destilada (T1:0,1; T2:0,2; T3: 0,3; T4:0,4; T5:zero $\left.\mathrm{ml} \mathrm{L}^{-1}\right)$. Verificou-se que o T3 $\left(0,3 \mathrm{~mL} \mathrm{~L}^{-1}\right)$ diferiu significativamente para o comprimento de raiz, enquanto que para os outros tratamentos não houve diferença significativa para germinação, IVG e comprimento da parte aérea.
\end{abstract}

Palavras-chave: biorreguladores, orgânicos, plântulas, raiz.

\section{EVALUATION OF CORN SEED GERMINATION TREATED WITH EXTRACT CONFREY (Symphytum officinale)}

\begin{abstract}
Maize crop is of superlative importance in Brazil and increases in productivity are necessary. Studies for the substitution of chemicals for organic products are being carried out, to decrease costs and environmental impact. The objective of this worl was to evaluate different concentrations of comfrey in the maize germination. The experiment was carried out in the Faculdade Centro Mato-Grossense (FACEM) at Sorriso (MT), in the Microbiology. The germination, germination velocity index (GVI) root and shoot length were evaluated in the five treatments, which are the following (T1:0.1, T2:0.2; T3: 0.3; T4:0.4; T5: zero $\left.\mathrm{ml} \mathrm{L}^{-1}\right)$ of the comfrey extract. It was observed that T3 $\left(0.3 \mathrm{~mL} \mathrm{~L}^{-1}\right)$ was significantly different from for root length and there were no differences for the other treatments in the parameters evaluated.
\end{abstract}

Keywords: bioregulators, organic, seedling, root. 


\section{INTRODUÇÃO}

A cultura do milho (Zea mays) tem uma grande importância econômica no Brasil. Segundo Nunes (2008) a importância do milho não está apenas na produção de uma cultura anual, mas sim em todo o relacionamento que essa cultura tem na produção agropecuária do Brasil, tanto no que diz respeito a fatores sociais quanto a fatores econômicos, devido a sua versatilidade de uso, pelos desdobramentos de produção animal e pelo aspecto social, o milho é um dos mais importantes produtos do setor agrícola brasileiro.

A cada safra surgem novas metas de produção das culturas, inclusive da cultura milho. Embora exista uma ampla diversidade no que diz respeito aos sistemas de produção desta cultura no Brasil, é possível identificar pontos que podem ser trabalhados, resultando em maior eficiência econômica das lavouras, sendo eles: uso de densidade e espaçamento de plantios adequados; implantação da cultura na época correta; uso de cultivares produtivos e adaptados à região e ao sistema de produção; correção e adubação do solo conforme análise prévia e o manejo adequado de doenças, plantas daninhas e insetos-praga (TORRES, 2009). Essa preocupação se extende desde a escolha de semente para plantio até o uso mais adequado dos conhecimentos disponíveis e já validados e que, na maioria das vezes, requer poucos investimentos financeiros, mas exige maior acompanhamento e capacitação gerencial dos agricultores.

O aumento expressivo da demanda por novas tecnologias e manejos culturais para maximizar a produtividade amplia as linhas de pesquisas científicas, a fim de melhorar a produção. Uma das grandes áreas estudadas está sendo a substituição de produtos químicos por produtos orgânicos, o que poderia reduzir o custo de produção e os riscos ambientais.

Segundo Cruz et al. (2015), com a possibilidade de aumento do valor agregado ao produto, a conservação ambiental e a baixa utilização de insumos, a produção orgânica pode-se impor como alternativa viável para o aumento da rentabilidade do setor agrícola. Nesse caso, a produção orgânica se aplica tanto à produção de alimentos consumidos diretamente pelo homem como a produção de alimentos para animais, possibilitando uma ampliação das cadeias produtivas de produtos orgânicos.

Oliveira et al. (2013) destacam que o confrei (Symphytum officinale) na agricultura ecológica surge como alternativa para os sistemas produtivos, tornando a aplicação de produtos via sementes uma prática rotineira, justificando o uso de bioestimulantes vegetais como uma alternativa a fim de potencializar a produtividade. 
O extrato de confrei vem sendo utilizado como uma fonte biológica alternativa no tratamento de sementes para diversas culturas, visando o aumento de produtividade da cultura (CORRÊA et al., 2008).

Este trabalho teve por objetivo avaliar o efeito de diferentes concentrações do extrato de confrei quando utilizados no tratamento de sementes de milho e sua influência na germinação, índice de velocidade de germinação (IVG), comprimento de parte aérea e comprimento de raiz.

\section{METODOLOGIA}

O experimento foi realizado no Laboratório de Microbiologia da Instituição Faculdade Centro Mato-Grossense (FACEM), localizada na cidade de Sorriso-MT em 2015. Foram utilizadas sementes comerciais de milho híbrido - Cargo Syngenta, tratadas comercialmente com fungicidas e inseticidas e obtidas por meio de doação.

O extrato de confrei foi produzido em laboratório de manipulação da cidade de Sorriso-MT, na forma líquida em concentração $100 \%$.

Os cinco tratamentos corresponderam a diferentes diluições do extrato bruto em água destilada: Tratamento 1 (T1): 0,1 $\mathrm{ml} \mathrm{L}^{-1}$; Tratamento 2 (T2): 0,2 $\mathrm{ml} \mathrm{L}^{-1}$; Tratamento 3 (T3): 0,3 $\mathrm{ml} \mathrm{L}^{-}$ ${ }^{1}$; Tratamento 4 (T4): 0,4 $\mathrm{ml} \mathrm{L}^{-1}$ e o Tratamento 5 (T5): zero $\mathrm{ml}$ de extrato de confrei. As sementes foram dispostas de maneira equidistante, em papéis germitest, totalizando 50 sementes por repetição de cada tratamento, sendo identificados individualmente. Cada tratamento era composto por cinco repetições.

A germinação foi conduzida inicialmente por embebição em solução com extrato de confrei por 30 minutos, nas diferentes concentrações acima descritas. A quantidade de solução do extrato de confrei para embeber as sementes foi determinada através da massa correspondente a 2,5 vezes a massa do papel não hidratado. As contagens de germinação foram realizadas aos 4 e 8 dias, sendo acrescentado água destilada, para a reposição de umidade.

Quanto à avaliação da germinação, foram consideradas germinadas aquelas sementes que apresentaram raiz primária com comprimento igual ou superior a $0,5 \mathrm{~cm}$ e plântula com comprimento igual ou superior a $1,0 \mathrm{~cm}$. Atendendo essas especificações, as sementes germinadas foram retiradas do germitest na última contagem, assim como a contagem das sementes que apresentaram fungos e as que não germinaram.

As sementes que apresentaram germinação normal tiveram suas plântulas e raízes mensuradas pelo seu comprimento $(\mathrm{cm})$, de forma individual e posteriormente foi determinada a 
média de cada repetição. O índice de velocidade de germinação (IVG) foi calculado segundo Nakagawa (1999).

Os experimentos foram conduzidos em delineamento inteiramente casualizado, sendo avaliados qualitativamente pelo teste Tukey a 5\% e através do aplicativo SISVAR (FERREIRA, 2011).

\section{RESULTADOS}

Os dados obtidos pela análise de variância (Figura 1) para as sementes germinadas e mortas permitiram verificar que as sementes de milho tratadas com extrato de confrei não diferiram significativamente entre si, pelo Teste Tukey a $5 \%$ de probabilidade.

Pode ser observado na Figura 1 que o T2 (0,2 $\left.\mathrm{ml} \mathrm{L}^{-1}\right)$ apresentou germinação superior de 1,6\% e índices de mortalidade das sementes 1,2\% inferior, quando comparado ao T5, dose zero.

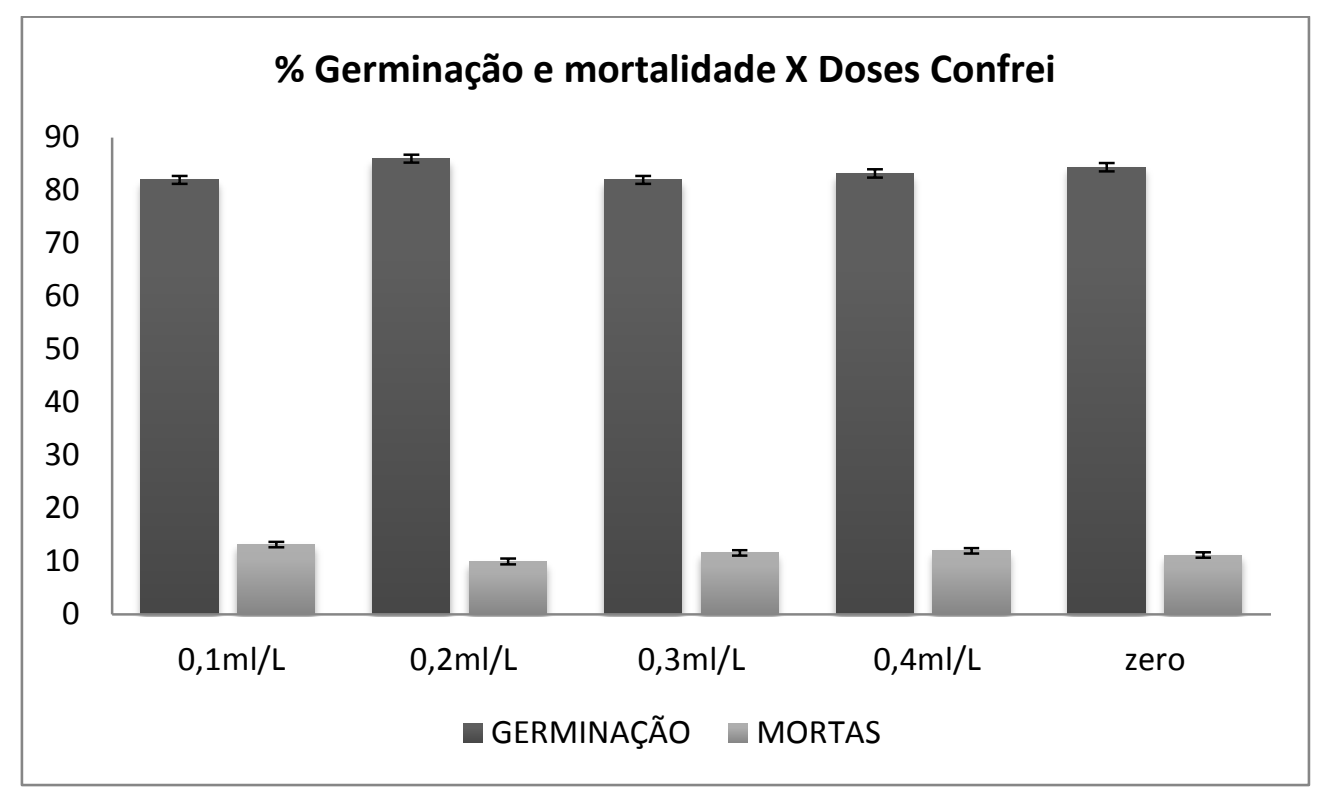

Figura 1. Percentagem de sementes germinadas e mortas de milho, em função das concentrações do extrato de confrei.

Para os dados de comprimento radicular e de parte aérea, observados na Figura 2, não ocorreram diferenças significativas no desenvolvimento de parte aérea para nenhuma das doses avaliadas. Entretanto, o desenvolvimento radicular apresentou diferenças significativas para T3 $(0,3 \mathrm{~mL} / \mathrm{L})$, quando comparada as demais doses avaliadas.

Assim, para o comprimento radicular o T3 $\left(0,3 \mathrm{ml} \mathrm{L}^{-1}\right)$ obteve a melhor resposta com média de $13 \mathrm{~cm}$ enquanto que o T5 apresentou média de 11,58 cm. O tratamento menos satisfatório para o comprimento radicular foi o $\mathrm{T} 2\left(0,2 \mathrm{ml} \mathrm{L}^{-1}\right) \mathrm{com} 11,43 \mathrm{~cm}$. 


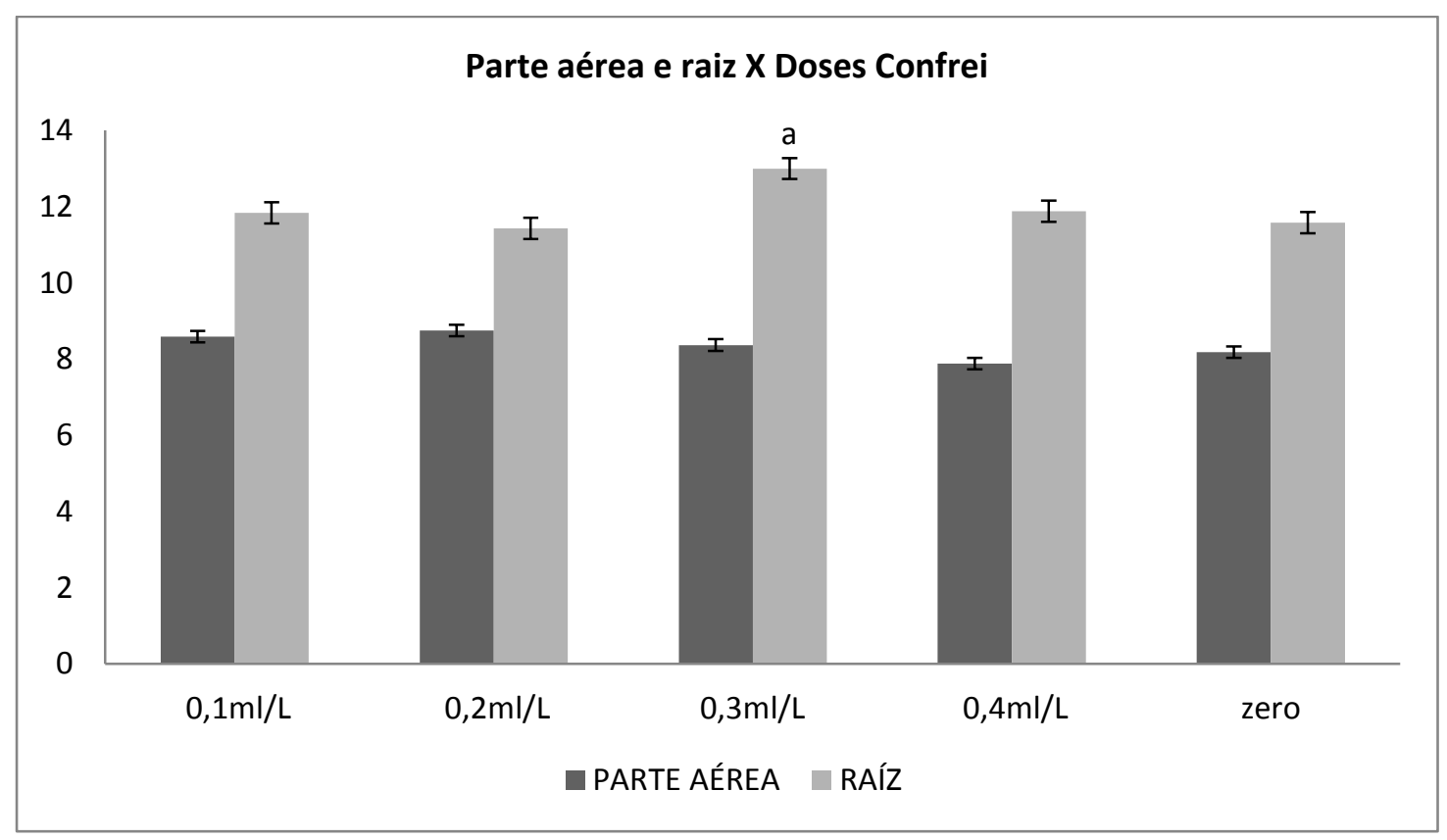

Figura 2. Comprimento de raiz e parte aérea de plântulas de milho em função das concentrações de extrato de confrei.

Para o Índice de velocidade de germinação (Figura 3) das sementes de milho tratadas com extrato de confrei, foi possível verificar que o menor valor de IVG ocorreu no T5 $(13,7)$ e o maior valor para foi obtido no T3 $(14,4)$. Porém, estaticamente não houve diferença significativa, resultado semelhante àquele obtido por Oliveira et al. (2013), onde não houve diferença significativa para o IVG em sementes de milho tratadas com diferentes dosagens de extrato de confrei.

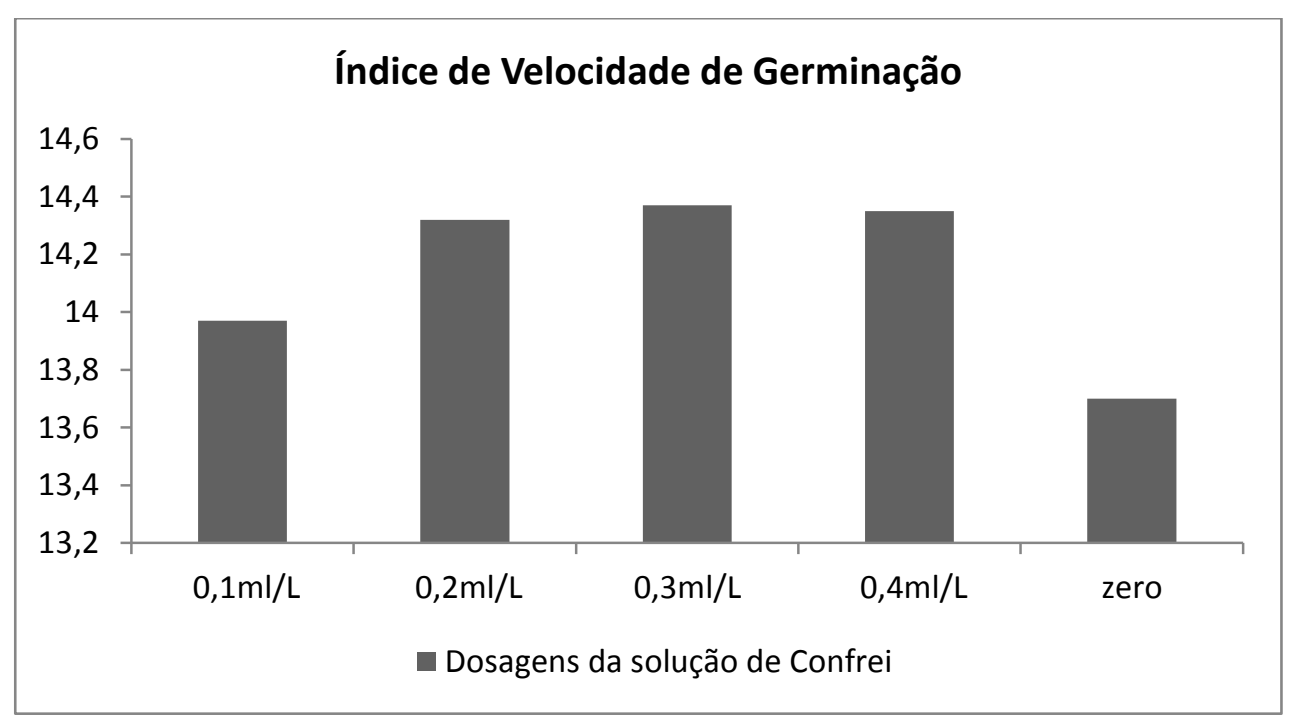

Figura 3. Índice de velocidade de germinação (IVG) em função das concentrações de extrato de confrei. 


\section{DISCUSSÃO}

A constatação do aumento da germinação no T2, refletindo consideravelmente na diminuição da percentagem de sementes mortas em 1,2\%, resultados diferentes foram observados por Mairesse et al. (2007) que ao testar os extratos de capuchinho, pariparoba, hortelã-pimenta, pata-de-vaca, fáfia, salvia-da-gripe, terramicina e pinus verificaram redução drásticas na germinação de sementes de alface.

Silva e Carvalho (2009), avaliando o efeito da aplicação do extrato de confrei sobre a germinação de sementes de girassol em laboratório observaram aumento na porcentagem de plântulas normais até a concentração de $100 \mathrm{~g} \mathrm{~L}^{-1}(88 \%)$, porém quando a concentração passou de $100 \mathrm{~g} \mathrm{~L}^{-1}$ para $200 \mathrm{~g} \mathrm{~L}^{-1}$ (82 \%) foi observado redução na porcentagem de germinação em relação à dosagem anterior (84\%), porém com relação às plântulas anormais e sementes mortas não houve diferença significativa em relação à testemunha.

O incremento do desenvolvimento radicular constatado neste experimento está em conformidade com dados encontrados por Oliveira et al. (2013), onde verificou que o extrato de confrei influenciou o desenvolvimento inicial de plântulas de milho, em concentração de 0,001 mL $\mathrm{L}^{-1}(19,16 \mathrm{~cm})$, apresentando maior desempenho radicular quando comparado a sua testemunha $(17,32 \mathrm{~cm})$.

O IVG não apresentou diferença significativa em sementes de milho tratadas com diferentes dosagens de extrato em experimento realizado por Oliveira et al. (2013), estando de acordo com os dados obtidos neste artigo.

\section{CONCLUSÃO}

As concentrações do extrato de confrei utilizadas no tratamento de sementes de milho não influenciaram a germinação, índice de velocidade de germinação e comprimento de parte aérea.

$\mathrm{Na}$ dose de $3 \mathrm{ml} \mathrm{L}^{-1}$ do extrato de confrei no tratamento de sementes de milho proporcionou maior desenvolvimento radicular.

Entretanto, nota-se neste trabalho que novos estudos devem ser realizados a fim de viabilizar a utilização do extrato de confrei no tratamento de sementes como uma alternativa sustentável e orgânica de trato cultural.

\section{REFERÊNCIAS}

CORRÊA, A. D.; BATISTA, R. S.; QUINTAS, L.E.M. Plantas Medicinais do Cultivo à Terapêutica. 7.ed. Petrópolis - RJ: Vozes, 247p. 2008. 
CRUZ, J. C.; FILHO, I. A. P; MATRANGOLO, W. J. R; MARRIEL, E. I.; MOREIRA, J. A. A. Milho Orgânico. Disponível em: < http://www.agencia.cnptia.embrapa.br/gestor/milho/arvore/CONT000fz5e6zsp02wx5ok0cpoo6ag wc2gy1.html>. Acesso em 16 Maio 2015.

FERREIRA, D.F. Sisvar: A computer statistical analysis system. Ciência e Agrotecnologia. n.6. Lavras: UFLA. 2011.

MAIRESSE, L.A.S.; COSTA, E.C.; FARIAS, J.R.; FIORIN, R.A. Bioatividade de extratos vegetais sobre alface (Lactuca sativa L). Revista da FZVA, Uruguaiana. v.14, n.2, p. 1-12. 2007. Disponível em: http://revistaseletronicas.pucrs.br/ojs/index.php/fzva/article/view/2494/1953

NAKAGAWA, J. Testes de vigor baseados no desempenho das plântulas. In: KRZYZANOWSKI, F. C.; VIEIRA, R. D.; FRANÇA, N. J. B. Vigor de sementes: conceitos e testes. Londrina: ABRATES. 1999 NUNES J. L. S. Importância econômica. Disponível em:

<http://www.agrolink.com.br/culturas/milho/importancia.aspx>. Acesso em 16 Junho 2015.

OLIVEIRA, A. L. T.; VASCONCELOS, A. A.; INNECCO. R.; LOPES, J. E. L. L.; SANTOS, M. A. M.; OLIVEIRA, G. S. Efeito do extrato de confrei na germinação e vigor de semente de milho. Revista Brasileira de Higiene e Sanidade Animal, Cerrá. v.7, n.1, 2013. Disponível em:

$<$ http://www.higieneanimal.ufc.br>. Acesso em: 26 Maio 2015.

SILVA, G. A.; CARVALHO R. I. N. Efeito alelopático de extratos de carqueja (Baccharis trimera) e confrei (Symphytum officinale) em sementes e plântulas de girassol. Revista Ciências Agrárias Ambientais, Curitiba. v.7, n.1, 2009. Disponível em:

<http://www2.pucpr.br/reol/index.php/ACADEMICA?dd1=2806\&dd99=pdf $>$. Acesso em 18 Maio 2015.

TORRES, M. Como aumentar a produtividade do milho. Disponível em: <http://hotsites.sct.embrapa.br/prosarural/programacao/2011/como-aumentar-a-produtividadedo-milho-2>. Acesso em 16 Jun 2015. 